\title{
Green Chemistry to the Resque of Disasters of the 1900 -2020 Period
}

\author{
Clement I. Beetseh Ph. D* \\ Federal University of Agriculture, Makurdi (FUAM) \\ Saratu S. Audu Ph. D \\ Nasarawa State University, Keffi (NSUK) \\ Mark A. Yoo MNSE \\ Lower Benue River Basin Development Authority (LBRBDA), Makurdi
}

\begin{abstract}
There is uncertainty about several aspects of the Covid-19 origin story that scientists are trying hard to unravel, including which species passed to humans. They are trying hard because knowing how a pandemic starts is a key to stopping the next one. Green chemistry emerged from a variety of existing ideas and research efforts characterization is one major analytical technique in our laboratories and so Scientists moved rapidly to characterize 2019-nCoV and widely disseminated their findings amongst the international research community as quickly as possible including the basic Viral Structure and Mechanism of Infection. Coronaviruses are large, enveloped, positive-stranded RNA viruses. They have the largest genome among all RNA viruses, typically ranging from 27 to $32 \mathrm{~kb}$. The genome is packed inside a helical capsid formed by the nucleocapsid protein $(\mathrm{N})$ and further surrounded by an envelope. One important example of this is the homology models of the novel coronavirus cysteine protease produced by Martin Stoermer etal (2020) . It is also established that disasters during the century 1900- 2020 were avoidable if the principles of green chemistry were applied to prevent future pandemics.
\end{abstract}

Keywords: Coronaviruses, Covid-19, Green chemistry, RNA, Pandemic, Characterization

DOI: $10.7176 / \mathrm{JEES} / 11-2-03$

Publication date: February $28^{\text {th }} 2021$

\section{Introduction}

A serious disruption over a period that causes widespread human, material and economic consequences describes a disaster and in a chemical industry negligence or misfortune can so easily result in devastating consequences. (Brice 2008) "If you measure the fears of the population about chemicals all over Europe, then air, water pollution and the risk of plant catastrophes are still the most important to them," says Daniel Verbist -, Executive Director responsible for communications at the European Chemical Industry council (CEFIC). But from each disaster, lessons can be learned, he says - and these can often lead to the introduction of more stringent health, safety and environment legislation. "The Seveso disaster [in Italy] in 1976 was a major environmental incident and that trigger made people realize that a Europe-wide environment policy was needed, it marked the birth of the Seveso directive," says Verbist and working from top to bottom of this write- up we are right now in a disaster-COVID 19 (CORONA VIRUS OUTBREAK) affecting over 200 countries and territories around the world and 2 international conveyances. According to WHO page on Novel Coronavirus (2019 - nCoV ) on January 23,2020 Wuhan (the city where the virus originated) the largest city in Central China, with a population of over 11 million people shutdown transport links, the city of Huang gang was also placed in quarantine, and the city of Ezhou closed its train stations. This means 18 million people had been placed in isolation. The World Health Organization (WHO) said cutting off a city as large as Wuhan is "unprecedented in public health history and praised China for its incredible commitment to minimize the spread to other countries. On Jan. 31, the United States declared Coronavirus a Public Health Emergency and issued 14 days quarantine rules for US citizens entering the US from China if entering from the Hubei province and issued an order to deny entry to foreigners who have traveled to China within the past two weeks. The novel coronavirus total case count surpassed that for severe acute respiratory syndrome coronavirus (SARS-Co V) (which affected 8,096 people worldwide). The Centre For Disease Control (CDC) confirmed the first US case of human to human transmission since then Germany, Japan, and Vietnam also started reporting cases in patients who didn't personally visit China, but contracted the virus from someone else who had visited Wuhan, China. The COVID-19 pandemic in Nigeria had its first confirmed case announced on 27 February, 2020, when an Italian citizen in Lagos tested positive for the virus. On 9 March, 2020, a second case of the virus was reported in Ewekoro, Ogun State, a Nigerian citizen who had contact with the Italian citizen. COVID-19 cases in Nigeria records deaths by $15^{\text {th }}$ October, 2020 up to 1113 . Recoveries and Active cases February to last 15 days of September are recorded in the tables and the references. These cases of human to human transmission are the most worrisome according to World Health Organization (G. Readfearn@readfearn) 


\section{Disasters from 1900 - 2020}

Chemistry has a key role to play in understanding everything from viral structure, pathogenesis, isolation of vaccines and therapies, to the development of materials and techniques used by basic researchers, virologists, and clinicians. ACS Chemical Biology Editor-in-Chief, Laura Kiessling, notes that "Fundamental research to understand the molecules that govern viral structure and function can accelerate the discovery of means to treat and prevent infectious disease. Events such as the current novel coronavirus outbreak highlight the essentiality of basic research and the need for sustained research funding so that comprehensive resources exist when a rapid response is required." On November 13, 2005 series of explosions rocked China-based Jilin Petrochemical's 70,000 tonne/year aniline complex in Northeast China, killing five and injuring seventy. Benzene also leaked into the Songhua river and caused millions of people to go without drinking water, with many fleeing their homes. Initial investigations suggested the explosion occurred after operators attempted to unblock a nitrobenzene rectification tower. Jilin's Bureau of Production Safety Supervision and Administration concluded that a valve was left open, causing temperatures to rise rapidly. Nearby equipment and storage tanks containing nitrobenzene, benzene and nitric acid feed stocks also caught fire and exploded. Water and electricity supplies had to be cut off as local residents reported tap water turning red or yellow. There were also concerns that water supplies to some Russian towns could be affected by the contamination of the river. Below are some selected disasters during the period 1900- 2020.

1.12002 - 2003 Coronaviruses pose serious health threats to humans and other animals. From 2002 to 2003 , severe acute respiratory syndrome corona virus (SARS-Co V) infected 8,000 people, with a fatality rate of $\sim 10 \%$. Since 2012, Middle East respiratory syndrome corona virus (MERS-Co V) has infected more than 1,700 people, with a fatality rate of $\sim 36 \%$. Since 2013 , porcine epidemic diarrhea corona virus (PEDV) has swept throughout the United States, causing an almost $100 \%$ fatality rate in piglets and wiping out more than $10 \%$ of America's pig population in less than a year. In general, coronaviruses cause widespread respiratory, gastrointestinal, and central nervous system diseases in humans and other animals, threatening human health and causing economic loss. Coronaviruses are capable of adapting to new environments through mutation and recombination with relative ease and hence are programmed to alter host range and tissue tropism efficiently. Therefore, health threats from corona viruses are constant and long-term. Understanding the virology of corona viruses and controlling their spread have important implications for global health and economic stability. SARS (November 2002 to July 2003): was a corona virus that originated from Beijing, China, spread to 29 countries, and resulted in 8,096 people infected with 774 deaths (fatality rate of 9.6\%). On January 29, 2020, Chinese officials confirmed 5,974 cases of the novel corona virus (2019-nCoV). One day later, on January 30, 2020 the virus cases surpassed even the 8,096 cases worldwide which were the final SARS count in 2003. MERS (in 2012) killed 858 people out of the 2,494 infected (fatality rate of $34.4 \%$ ).)

1 .2 March 23, 2005 disaster at UK oil major BP's Texas City refinery, in Texas, US, was considered the nation's worst industrial disaster in 15 years. A series of explosions occurred when a hydrocarbon isomerization unit was restarted and a distillation tower flooded with hydrocarbons. As a result, 15 were killed and another 180 were injured. BP admitted to charges and accepted fines last year, with BP America chairman Bob Malone conceding that the company was guilty of a felony "for failing to have adequate written procedures for maintaining the ongoing mechanical integrity of process equipment at the Texas City refinery. "If our approach to process safety and risk management had been more disciplined and comprehensive, this tragedy could have been prevented," he said.

1 .3 December 3, 1984 gas leak at US-based Union Carbide's pesticide plant in Bhopal, India, is cited as one of the chemical industry's greatest tragedies. On December 3, 1984, methyl isocyanate gas leaked from the facility during the early hours of the morning while local residents slept. Around 2,000 people died immediately, with another 8,000 dying later. The initial investigation suggested that large volumes of water had entered the chemical tank, which caused a chemical reaction and led to the leak. The incident highlighted the problem of urbanization and having a plant located near a densely populated area. In 2001, Union Carbide became a wholly owned subsidiary of US giant Dow Chemical.

1 .4 April 16, 1947 TEXAS CITY, US. On the morning of April 16, 1947, a French ship - The Grandcamp - was being loaded with ammonium nitrate (AN) fertilizer. With over 2,000 tonnes of AN onboard, a fire started in the hold. Not wanting to damage the cargo, the captain refused to use water on the flames and opted instead to control the fire using the steam system. The heat intensified and the ship exploded, killing crewmembers and showering onlookers with shrapnel. The blast was heard over $240 \mathrm{~km}$ away. A $4.6 \mathrm{~m}$ wave swept a barge ashore, buildings were destroyed - including a Monsanto chemical plant nearby - and the ship's anchor was found far away. There were around 3,500 injuries and 576 people were killed. 
1 .5 September 21, 1921 workers at BASF's Oppau site, in Germany, decided that the best course of action to loosen a 4,500 tonne mound of ammonium nitrate (AN) and ammonium sulfate that had solidified was to detonate several dynamite charges. Unfortunately, the use of this tried-and-true method was not suited to the explosive nature of Ammonium Nitrate, resulting in a massive 125m -long and 19m-deep crater and the deaths of more than 500 people. The accident destroyed around $80 \%$ of the homes in Oppau and ripped the roofs off houses as far as $25 \mathrm{~km}$ away. Ammonium Nitrate has since been responsible for numerous explosions in the chemical sector globally, as well as many acts of terrorism. Strict measures have been imposed to ensure the safe handling and storage of fertilizer.

\subsection{SARS-CoV-2 (Covid-19).}

Scientists and public health officials are working hard to identify the source of the SARS-CoV-2 which is the virus that causes COVID-19. The initial transmission appeared to be from an animal source, but there has been personto-person transmission in countries. According to American Chemical Society, (ACS Publications Chem. R xiv) Chemistry has a key role to play in understanding everything from viral structure to pathogenesis, isolation of vaccines and therapies, as well as in the development of materials and techniques used by basic researchers, virologists and clinicians. It also aimed to provide a brief overview of the important contributions of chemistry to understanding and controlling the spread of corona viruses. In light of the current outbreak of a novel corona virus (2019-nCoV) in China, ACS Publications is releasing a free-to-read Virtual Issue, featuring a collection of articles on coronavirus research. This Virtual Issue provides a brief overview of the important contributions of chemistry to understanding and controlling the spread of corona viruses. ACS Infectious Diseases Associate Editor and virologist, Priscilla Yang, says "This Virtual Issue shines a light on various research efforts past \& present to facilitate rapid development of diagnostics and therapeutics for corona virus, and the important role that chemistry has to play in translational discovery."

2.1 Corona viruses belong to the family Corona viridae in the order Nido virales. They can be classified into four genera: Alpha coronavirus, Beta coronavirus, Gamma coronavirus, and Delta coronavirus. Among them, alphaand beta corona viruses infect mammals, gamma corona viruses infect avian species, and delta corona viruses infect both mammalian and avian species. Representative alpha corona viruses include human coronavirus NL63 (HCoV-NL63), porcine transmissible gastroenteritis coronavirus (TGEV), PEDV, and porcine respiratory coronavirus (PRCV). Representative beta corona viruses include SARS-Co V, MERS-Co V, bat corona virus HKU4, mouse hepatitis coronavirus (MHV), bovine coronavirus (B Co V), and human coronavirus OC43. Representative gamma- and delta coronaviruses include avian infectious bronchitis coronavirus (IBV) and porcine delta coronavirus (Pd CV), respectively. Coronaviruses are large, enveloped, positive-stranded RNA viruses. They have the largest genome among all RNA viruses, typically ranging from 27 to $32 \mathrm{~kb}$. The genome is packed inside a helical capsid formed by the nucleocapsid protein $(\mathrm{N})$ and further surrounded by an envelope. Associated with the viral envelope are at least three structural proteins: The membrane protein $(\mathrm{M})$ and the envelope protein $(\mathrm{E})$ are involved in virus assembly, whereas the spike protein $(\mathrm{S})$ mediates virus entry into host cells. Some coronaviruses also encode an envelope-associated hem agglutinin-esterase protein (HE). Among these structural proteins, the spike forms large protrusions from the virus surface, giving coronaviruses the appearance of having crowns (hence their name; corona in Latin means crown). In addition to mediating virus entry the spike is a critical determinant of viral host range and tissue tropism and a major inducer of host immune responses.

\subsection{Mechanism of Infection}

The rapid availability of $\mathrm{nCoV}$ genomic data made possible the production of first-generation homology models for 3CLpro cysteine protease; an enzyme which is crucial for viral replication and has been explored previously as a target for antiviral therapies in the treatment of another corona virus, SARS. This preprint notes that though the viral genome bears a close similarity to bat corona viruses, the protease exhibits the closest homology with SARS CoV protease a zoonotic virus that entered the human population via civets. Huang et al. (2014) used crystallographic and biophysical methods to conduct structural and functional characterization of HKU9-RBD a bat coronavirus that has not crossed over to humans. The rationale for these studies was that bat beta corona viruses (a genus that includes SARS and MERS) should be well characterized in the event that they end up being the source of the next global pandemic. Upon comparison of the HKU9-RBD receptor-binding domain (RBD) to the available structures of the SARS-, MERS-, and HKU4- (another bat coronavirus) RBDs, the authors found that even though the evolutionary histories of RNA viruses tend to be difficult to determine due to substantial evolutionary pressure, the corona viruses in this study exhibited several conserved tertiary structural features in the core sub domain of the spike (S) protein. This spike protein, present on the virus surface, is a key factor in determining the species tropism of the virus as it is involved in receptor recognition and membrane fusion as part of the mechanism of infection. The authors concluded that their findings supported the notion that the $\mathrm{S}$ protein of betaCoV divergently evolves from a common ancestor, particularly in the external RBD region, and that this 
determines the potential of a particular beta Co V virus for interspecies transmission. Lee et al. conducted highthroughput screening of 25,000 compounds, seeking a small molecule dual inhibitor for the papain-like protease (PL pro) enzymes of MERS-CoV and SARS-CoV. The authors were able to identify a compound with inhibitory activity against both enzymes though interestingly, despite the fact that the two enzymes bear significant similarities in their overall structures and catalytic sites, the identified compound acts as a competitive inhibitor against MERS-Co V PL pro, and an allosteric inhibitor against SARS-Co V PL pro as determined using SPR. Further, though this suggests that the inhibitor recognition specificity of the compound may differ for MERS-Co V PL pro and SARS-Co V PL pro, the inhibitor was selective for both of these over two human homologs. Two residues identified through structure and sequence alignments, Y269 and Q270 of the SARS-Co V PL pro were replaced by T274 and A275 in MERS-Co V PL pro complicating the potential for critical binding interactions. Taking this into consideration along with the finding that none of the four tested SARS-Co V PL pro lead inhibitors were effective against MERS-Co V PL pro, it is notable that a dual functionality inhibitor was identified for both of the SARS and MERS papain-like proteases.

\subsection{Illness in humans}

These viruses cause respiratory illness in humans, including the common cold and more serious diseases, such as Middle East Respiratory Syndrome (MERS) and Severe Acute Respiratory Syndrome (SARS). This group of viruses can also infect animals and are zoonotic, meaning they can be transmitted between animals and humans .The development of therapeutics for known corona viruses, as well as 2019-nCoV, is an active research area , a review by Morse et al. deposited on Chem $\mathrm{R}$ xiv discusses potential prevention and treatment options for 2019-nC. The development of green chemistry in Europe and the United States was linked to a shift in environmental problem-solving strategies: a movement from command and control regulation and mandated reduction of industrial emissions at the "end of the pipe," toward the active prevention of pollution through the innovative design of production technologies themselves. The set of concepts now recognized as green chemistry coalesced in the mid- to late-1990s, along with broader adoption of the term.

\section{0 Green chemistry}

Green chemistry dates from 1991, when the U.S. Environmental Protection Agency (EPA) launched the Alternative Synthetic Pathways for Pollution Prevention research program under the auspices of the Pollution Prevention Act of 1990. This program marked a radical departure from previous EPA initiatives in emphasizing the reduction or elimination of the production of hazardous substances, as opposed to managing these chemicals after they were manufactured and released into the environment. This research program later expanded to include the development of greener solvents and safer chemicals. The name green chemistry was officially adopted in 1996. The goal of the Pollution Prevention Act of 1990 was not simply to regulate the quantity and type of emissions but to place limits on the industry in order to reduce the amount of pollution it generated. American chemist Paul Anastas, one of the principal founders of green chemistry, claimed that by improving how chemicals are synthesized, it might be possible to prevent the production of pollutants

\section{3 .1 The principles of green chemistry to help prevent these future pandemics}

The Environmental Protection Agency has played a significant early role in fostering green chemistry through its pollution prevention programs, funding, and professional coordination. Researchers at the University of York contributed to the establishment of the Green Chemistry Network (GCN) within the Royal Society of Chemistry, and the launch of the journal Green Chemistry.

In 1998, Paul Anastas (who then directed the Green Chemistry Program at the US EPA) and John C. Warner (then of Polaroid Corporation) published a set of principles to guide the practice of green chemistry The twelve principles address a range of ways to reduce the environmental and health impacts of chemical production, and also indicate research priorities for the development of green chemistry technologies . principles which cover such concepts as: the design of processes to maximize the amount of raw material that ends up in the product; the use of renewable material feedstocks and energy sources; the use of safe, environmentally benign substances, including solvents, whenever possible; the design of energy efficient processes; applying Less hazardous chemical syntheses. Synthetic methods should avoid using or generating substances toxic to humans and/or the environment but designing safer chemicals. Chemical products should be designed to achieve their desired function while being as non-toxic as possible.

\section{The Green solvents approach}

Green solvents are generally less harmful to health and the environment preferably more sustainable. The environmental impact of solvent manufacture must be considered when a solvent is being selected for a product or process- the solvent that makes a product or process have the least environmental impact over its entire life cycle no solvent can be declared to be a "green solvent" unless the declaration is limited to a specific application. 
Bioengineering is also seen as a promising technique for achieving green chemistry goals. A number of important process chemicals can be synthesized in engineered organisms, such as shikimate, a Tamiflu precursor which is fermented by Roche in bacteria as a style of chemical synthesis that is consistent with the goals of green chemistry. The concept of 'green pharmacy' has recently been articulated based on similar principles. Succinic acid is a platform chemical that is an important starting material in the formulations of everyday products. Traditionally, succinic acid is produced from petroleum-based feedstocks. BioAmber has developed process and technology that produces succinic acid from the fermentation of renewable feedstocks at a lower cost and lower energy expenditure than the petroleum equivalent while sequestering $\mathrm{CO}_{2}$ rather than emitting it. Several laboratory chemicals are controversial from the perspective of Green chemistry. Ethidium bromide, xylene, mercury, and formaldehyde have been identified as "worst offenders" which have alternatives. Solvents in particular make a large contribution to the environmental impact of chemical manufacturing and there is a growing focus on introducing Greener solvents into the earliest stage of development of these processes: laboratory-scale reaction and purification methods in the Pharmaceutical Industry, both GSK and Pfizer have published Solvent Selection Guides for their Drug Discovery chemists. In 2007, The EU put into place the Registration, Evaluation, Authorisation and Restriction of Chemicals (REACH) program, which requires companies to provide data showing that their products are safe. This regulation (1907/2006) ensures not only the assessment of the chemicals' hazards as well as risks during their uses but also includes measures for banning or restricting/authorising uses of specific substances. The U.S. law that governs the majority of industrial chemicals (excluding pesticides, foods, and pharmaceuticals) is the Toxic Substances Control Act (TSCA) of 1976. Examining the role of regulatory programs in shaping the development of green chemistry in the United States, analysts have revealed structural flaws and long-standing weaknesses in TSCA; for example, a 2006 report to the California Legislature concludes that TSCA has produced a domestic chemicals market that discounts the hazardous properties of chemicals relative to their function, price, and performance Scholars have argued that such market conditions represent a key barrier to the scientific, technical, and commercial success of green chemistry in the U.S., and fundamental policy changes are needed to correct these weaknesses. Passed in 1990, the Pollution Prevention Act helped foster new approaches for dealing with pollution by preventing environmental problems before they happen. In 2008, the State of California approved two laws aiming to encourage green chemistry, launching the California Green Chemistry Initiative. One of these statutes required California's Department of Toxic Substances Control (DTSC) to develop new regulations to prioritize "chemicals of concern" and promote the substitution of hazardous chemicals with safer alternatives. The resulting regulations took effect in 2013, initiating DTSC's Safer Consumer Products Program.

\section{Discussion}

We have so far established that the initial transmission of these viruses cause respiratory illness in humans, including the common cold and more serious diseases, such as Middle East Respiratory Syndrome (MERS) and Severe Acute Respiratory Syndrome (SARS) appearing to be from an animal source, but there has been personto-person transmission. And according to American Chemical Society, (ACS Publications Chem. R xiv) Chemistry has a key role to play in understanding everything from viral structure to pathogenesis, isolation of vaccines and therapies, as well as in the development of materials and techniques used by basic researchers, virologists and clinicians. It also aims to provide a brief overview of the important contributions of chemistry to understanding and controlling the spread of corona viruses. In light of the current outbreak of a novel corona virus (2019-nCoV) in China, ACS Publications is releasing a free-to-read Virtual Issue, featuring a collection of articles on corona virus research This Virtual Issue provides a brief overview of the important contributions of chemistry to understanding and controlling the spread of corona viruses. ACS Infectious Diseases Associate Editor and virologist, Priscilla Yang, says "This Virtual Issue shines a light on various research efforts past \& present to facilitate rapid development of diagnostics and therapeutics for corona virus, and the important role that chemistry has to play in translational discovery." knowing how a pandemic starts is a key to stopping the next one. A variety of existing ideas and research efforts like characterization is one major analytical technique in our laboratories and so Scientists moved rapidly to characterize $2019-\mathrm{nCoV}$ and widely disseminated their findings amongst the international research community as quickly as possible including the basic Viral Structure and mechanism of Infection, that corona viruses are large, enveloped, positive-stranded RNA Huang et al. used crystallographic and biophysical methods to conduct structural and functional characterization of HKU9-RBD - a bat corona virus that has not crossed over to humans. The rationale for these studies was that bat beta corona viruses (a genus that includes SARS and MERS) should be well characterized in the event that they end up being the source of the next global pandemic. Upon comparison of the HKU9-RBD receptor-binding domain (RBD) to the available structures of the SARS-, MERS-, and HKU4- (another bat corona virus) RBDs, the authors found that even though the evolutionary histories of RNA viruses tend to be difficult to determine due to substantial evolutionary pressure, the corona viruses in this study exhibited several conserved tertiary structural features in the core sub domain of the spike (S) protein. This spike protein, present on the virus surface, is a key factor in determining the species 
tropism of the virus as it is involved in receptor recognition and membrane fusion as part of the mechanism of infection. The authors concluded that their findings supported the notion that the $\mathrm{S}$ protein of betaCoV divergently evolves from a common ancestor, particularly in the external RBD region, and that this determines the potential of a particular beta Co V virus for interspecies transmission. Lee et al (2020) conducted high-throughput screening of 25,000 compounds, seeking a small molecule dual inhibitor for the papain-like protease (PL pro) enzymes of MERS-CoV and SARS-CoV. The authors were able to identify a compound with inhibitory activity against both enzymes though interestingly, despite the fact that the two enzymes bear significant similarities in their overall structures and catalytic sites, the identified compound acts as a competitive inhibitor against MERS-Co V PL pro, and an allosteric inhibitor against SARS-Co V PL pro as determined using SPR. Further, though this suggests that the inhibitor recognition specificity of the compound may differ for MERS-Co V PL pro and SARS-Co V PL pro, the inhibitor was selective for both of these over two human homologs.

Development of green chemistry in Europe and the United States was linked to a shift in environmental problem-solving strategies: a movement from command and control regulation and mandated reduction of industrial emissions at the "end of the pipe," toward the active prevention of pollution through the innovative design of production technologies themselves. The set of concepts now recognized as green chemistry coalesced in the mid- to late-1990s, along with broader adoption of the term

\section{Conclusion}

Negligence or misfortune can so easily result in devastating consequences and has effects through generations of populations which are most irreparable and the cost of that to the affected people is unimaginable. The story of corona virus seems well fixed: in late 2019, someone at the now world-famous Huanan seafood market in Wuhan was infected with a virus from an animal. The rest is part of an awful history still in the making, with Covid-19 spreading from that first cluster in the capital of China's Hubei province to a pandemic that has killed about one million people so far. Prof Stephen Turner, head of the department of microbiology at Melbourne's Monash University, says what's most likely is that virus originated in bats. But that's where his certainty ends, he says. On the hypothesis that the virus emerged at the Wuhan live animal market from an interaction between an animal and a human, Turner says: "I don't think it's conclusive adding that viruses of this type are circulating all the time in the animal kingdom In fact, some species of animals, such as bats, act as reservoirs for carrying wide varieties of viruses, and severe viral outbreaks in the human population such as for SARS and MERS tend to occur when these viruses jump from animals to humans when given the opportunity due to close interaction. The novel corona virus (currently referred to as 2019-nCoV) was first detected in Wuhan, China, in December 2019 and appeared to initially affect people who had visited a seafood and animal market selling live game, but person-to-person spreading occurred as well. Investigations on the source 2019-nCoV are actively ongoing, and knowledge of the virus, such as its transmissibility and incubation period, is constantly developing .As stated above characterization and possible prevention measures of 2019-nCoV or any other outbreaks are published,we therefore take advantage of these closely and implement same looking forward to a restful future .

\section{Recommendations}

Disasters have occurred due to defects in design; absence of Standard operating procedures SOP's to mitigate an early warning in the process and poor co-ordination between different departments within the company. Modern technologies in industry have also increased vulnerability, inadequate steps, human errors, improper maintenance of equipments in industry, leading to equipment malfunction and ultimately failure, resulting in catastrophic explosions. The industry must have a good emergency response team that can react swiftly to mitigate propagating disasters. Maintenance of the Plant Facility \& Equipment, proper maintenance, regular site safety and health inspection need to be carried out to ensure that plant facility is safe and equipments are operating as intended. Compliance with existing rules and regulations, a knowledgeable and dedicated team of qualified professionals to evaluate the hazards and risks arising from day to day activities is essential. An online portal, where experts from around the world can help industries to prevent such unforeseen circumstances and Research and Development to develop newer technologies so that toxicity and transmissions can be minimized.

\section{References}

$\wedge$ Achille - Brice. onlinelibrary.wiley.com > abs > j.1365-2141.2008. 06998.x First published: 13 February, 2008

$\wedge$ Dr. Martin Stoermer - UQ Researchers m.stoermer@imb.uq.edu.au. (2020).

$\wedge$ Y.-T. Huang $(*) \cdot$ D.J. Lowe - L.A. Schipper 2014. Department of Earth and Ocean Sciences, University of Waikato, Private Bag 3105, Hamilton 3240, New Zealand.

$\wedge$ WHO page on Novel Coronavirus (2019-nCoV) United Nations Geoscheme October, 2020 Author: Andy Brice 2008/10/02

^ Graham Readfearn@readfearn Tue 28 Apr, 202001.46 BST

^Sheikh, Knvul; Rabin, Roni Caryn (10 March, 2020). "The Coronavirus: What Scientists Have Learned So Far". 
The New York Times. Retrieved 24 May, 2020.

$\wedge$ "NCDC Covid-19 Page". Nigeria Centre for Disease Control. Retrieved 8 October, 2020.

$\wedge$ "First case of coronavirus disease confirmed in Nigeria". Nigeria Centre for Disease Control. 28 February, 2020. Retrieved 10 March, 2020.

^ Maclean, Ruth; Dahir, Abdi Latif (28 February, 2020). "Nigeria Responds to First Coronavirus Case in SubSaharan Africa". The New York Times. Retrieved 10 March, 2020.

$\wedge$ "Nigeria records second case of Coronavirus". P.M. News. 9 March, 2020. Retrieved 10 March, 2020

$\wedge$ Novel Coronavirus (2019-nCoV) situation reports - World Health Organization (WHO).

^ 2019 Novel Coronavirus (2019-nCoV) in the U.S. -. U.S. Centers for Disease Control and Prevention (CDC).

$\wedge$ Outbreak Notification - National Health Commission (NHC) of the People's Republic of China.

$\wedge$ Novel coronavirus (2019-nCoV) - Australian Government Department of Health

$\wedge$ Novel coronavirus 2019-nCoV: early estimation of epidemiological parameters and epidemic prediction Jonathan M. Read et al, Jan. 23,2020.

$\wedge$ Early Transmissibility Assessment of a Novel Coronavirus in Wuhan, China - Maimuna Majumder and Kenneth D. Mandl, Harvard University - Computational Health Informatics Program - Posted: 24 Jan 2020 Last revised: 27 Jan 2020

$\wedge$ Wuhan lockdown 'unprecedented', shows commitment to contain virus: WHO representative in China - Reuters. January 23, 2020

$\wedge$ Human-to-human transmission of Wuhan virus outside of China, confirmed in Germany, Japan and Vietnam The Online Citizen, Jan. 29, 2020

${ }^{\wedge}$ CDC Confirms Person-to-Person Spread of New Coronavirus in the United States - CDC Press Release, Jan. 30 , 2020

^ Wilson, M. P.; Schwarzman, M. R. (2009). "Toward a new U.S. Chemicals policy: Rebuilding the foundation to advance new science, green chemistry, and environmental health". Environmental Health Perspectives. 117 (8): 1202-9. doi:10.1289/ehp.0800404. PMC 2721862. PMID 19672398.

^ "Green Chemistry". United States Environmental Protection Agency. 2006-06-28. Retrieved 2011-03-23

$\wedge$ Sheldon, R. A.; Arends, I. W. C. E.; Hanefeld, U. (2007). Green Chemistry and Catalysis. doi:10.1002/9783527611003. ISBN 9783527611003. S2CID 92947071.

^ Clark, J. H.; Luque, R.; Matharu, A. S. (2012). "Green Chemistry, Biofuels, and Biorefinery". Annual Review of Chemical and Biomolecular Engineering. 3: 183-207. doi:10.1146/annurev-chembioeng-062011-081014. PMID 22468603.

$\wedge$ Cernansky, R. (2015). "Chemistry: Green refill". Nature. 519 (7543): 379-380. doi:10.1038/nj7543-379a. PMID 25793239.

$\wedge$ Sanderson, K. (2011). "Chemistry: It's not easy being green". Nature. 469 (7328): 18-20. Bibcode:2011Natur.469...18S. doi:10.1038/469018a. PMID 21209638.

^ Poliakoff, M.; Licence, P. (2007). "Sustainable technology: Green chemistry". Nature. 450 (7171): 810-812. Bibcode:2007Natur. 450..810P. doi:10.1038/450810a. PMID 18064000.

^ Clark, J. H. (1999). "Green chemistry: Challenges and opportunities". Green Chemistry. 1: 1-8. doi:10.1039/A807961G

$\wedge$ COVID-19 cases in Nigeria records Deaths by $15^{\text {th }}$ October 2020 up to 1113 , Recoveries and Active cases February to last 15 days of September 2020.

\section{Date}

2020-09-23

2020-09-24

2020-09-25

2020-09-26

2020-09-27

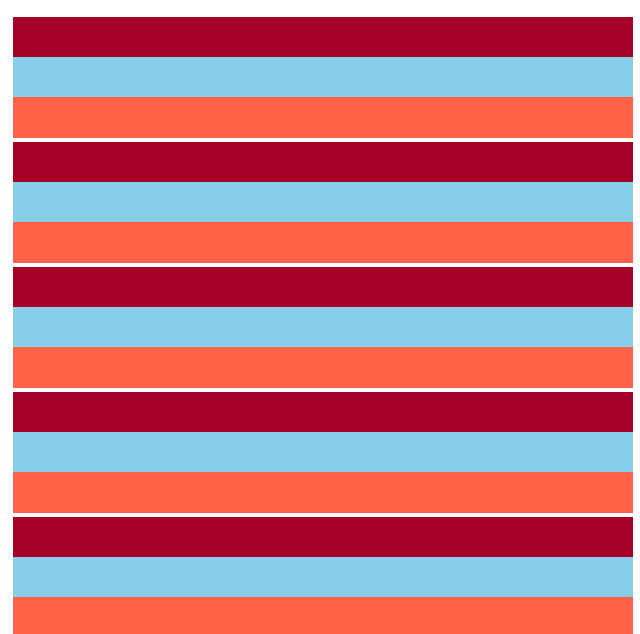

\# of cases \# of deaths

$\begin{array}{lc}57,724(+0.19 \%) & 1,102(+0.18 \%) \\ 57,849(+0.22 \%) & 1,102(=) \\ 58,062(+0.37 \%) & 1,103(+0.09 \%) \\ 58,198(+0.23 \%) & 1,106(+0.27 \%) \\ & \\ 58,324(+0.22 \%) & 1,108(+0.18 \%)\end{array}$




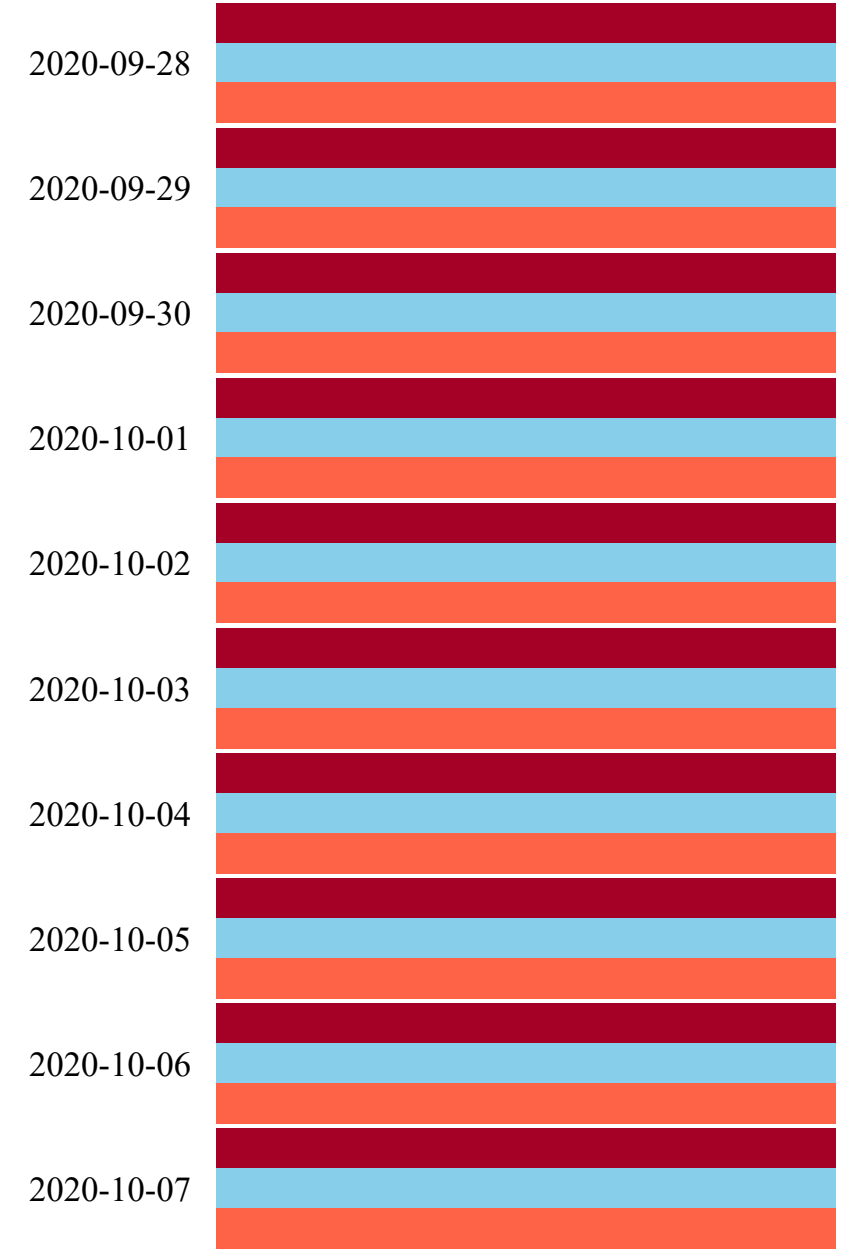

$\begin{array}{lc}58,460(+0.23 \%) & 1,111(+0.27 \%) \\ 58,647(+0.32 \%) & 1,111(=) \\ 58,848(+0.34 \%) & 1,112(+0.09 \%) \\ 59,001(+0.26 \%) & 1,112(=) \\ 59,127(+0.21 \%) & 1,112(=) \\ 59,287(+0.27 \%) & 1,113(+0.09 \%) \\ 59,345(+0.1 \%) & 1,113(=) \\ 59,465(+0.2 \%) & 1,113(=) \\ 59,583(+0.2 \%) & 1,113(=) \\ 59,738(+0.26 \%) & 1,113(=)\end{array}$

Sources: various news sources and state health department websites.

The list of countries and territories and their continental regional classification is shown below:

- 35,958 new cases and 645 new deaths in the United States

- 79,774 new cases and 1,069 new deaths in India

- 2,832 new cases and 10 new deaths in Germany

- 12,148 new cases and 136 new deaths in France

- 2 new cases in French Guiana

- 6,795 new cases and 199 new deaths in Brazil

- 1,442 new cases and 63 new deaths in Turkey

- 1,291 new cases and 12 new deaths in Lebanon

- 1,762 new cases and 21 new deaths in Czechia

- 12 new cases in Channel Islands

- 6,968 new cases and 66 new deaths in the United Kingdom

- 17 new cases in Cyprus

- 2,499 new cases and 23 new deaths in Italy

- 1,840 new cases and 45 new deaths in Chile

- 2,343 new cases and 53 new deaths in Romania

- 1,396 new cases and 33 new deaths in Bangladesh

- 2,292 new cases and 27 new deaths in Poland

- 4,317 new cases and 116 new deaths in Indonesia

- 9,412 new cases and 186 new deaths in Russia

- 2,607 new cases and 7 new deaths in Belgium

- 5,099 new cases and 432 new deaths in Mexico 